\title{
Handling Emotional Abuse: An Investigation into Workplace Bullying/Mobbing
}

\author{
Sanam Pathan \\ Ms. Azra Maqsood
}

\begin{abstract}
The research summarizes the findings and literature on the nature and causes of bullying/mobbing and the prevalence of being emotionally abused at workplace. Bullying occurs when someone at work is systematically subjected to aggressive behavior from one or more colleagues or superiors over a long period of time, in a situation where the target finds it difficult to defend him or herself or to escape the situation. Such treatment tends to stigmatize the target and may even cause severe psychological trauma. The research focused on definitional issues, including the type, frequency, and duration of bullying/mobbing acts, culture and role of organization in combating the phenomenon. The research study also highlights the key traits of a typical bully/mob and the strategies/ tactics that make them successful in the bullying/ mobbing process. Also, what influences bullying/mobbing has on the individual or group victims' work and personal life, along with a definite cost to the organization of employment. The research also highlights that there are certain organizational and social factors, as well as personal factors contributing to the vicious prevalence of emotional abuse in different organizations.
\end{abstract}

Keywords: Bullying, mobbing, emotional abuse, harassment, interpersonal conflict, effects of bullying/mobbing, traits of bully/mob, strategies for bulling/mobbing.

\section{Introduction}

Workplace bullying/ mobbing as an integral component of emotional abuse have gained tremendous attention, both from the public and research, over the last few years. All this is geared and motivated by the existence of literature and studies pointing to severe harmful and negative repercussions associated with the phenomena (Ashforth, 1995; Einarsen and Raknes, 1997; Mikkelsen and Einarsen, 2001). However, it is also imperative to highlight that there are not yet sufficient studies concerning the phenomena of bullying and mobbing in Asian as well as Pakistani literature. Hence, most of the working people do not recognize that this imperceptible conduct and concept actually exists. One of the most important explanations for this could be insufficient academic surveys and understanding of the subject as well as awareness of the terms among different employees. Curiously IR and HRM scholars have rarely undertaken systematic investigation or analysis of the issue, despite the fact that it appears to be an issue directly within the horizon of these disciplines. (Schat, et al., 2003) Exploring the literature it was found that the concept of emotional abuse, particularly

Sanam Pathan is an MS/MS student at SZABIST.

Azra Maqsood is Assistant Professor.

Journal of Independent Studies and Research - MSSE

Volume 8

Number 1

January 2010 117 
the workplace bullying and mobbing, though existed for a lot of time now, yet it is relatively a recent phenomenon. In 1986, Leymann introduced first time the concept of workplace bullying in the Scandinavian and German context. Since the 1990s, a considerable number of studies have been undertaken in many countries, such as Sweden (Leymann, 1990), Norway (Einarsen and Raknes, 1997), Finland (Bjorkqvist, Osterman, and Hjelt-Back, 1994; Vartia, 1996), Germany (Zapf, Knorz, and Kulla, 1996), Austria (Niedl, 1996) and Australia (McCarthy, Sheehan, and Keashly and Harvey, 2006). In the last decade workplace bullying research has increased in significance internationally across academics and practitioners and the phenomenon has been recognized as serious problem even at the societal level.

The father of the concept, Leymann (1990) put forward that the mere root cause of bullying and mobbing at workplace is working conditions. Other research, (Vartia 1996; O'Moore, Seigne, McGuire and Murray, 1998) found that bullying /mobbing is prevalent when the working environment is strained and competitive; where superiors/bosses treat their inferiors/subordinates unjustly; and when changes within an organization have occurred under a poor leadership or a high authoritarian leadership.

\section{Theoretical Framework}

Figure 1: Theoretical Framework for Research

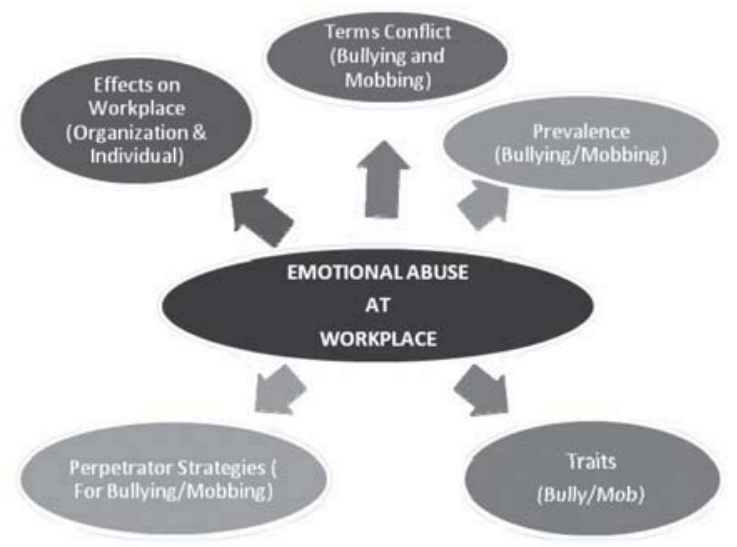

For basic understanding of the research and study, the researcher after going through the literature and reviews, defined a scope and objective for research consideration. Variables of study were identified to be research and analyzed in relevance to the study of workplace emotional abuse. Five variables for the study were identified to be studied in the literature review as well as looked into survey questionnaire and analysis, as follows:

- $\quad$ Existence of the term conflict between emotional abuse, bullying and mobbing and what each means generally and in respect to the study.

- $\quad$ Prevalence of workplace bullying/mobbing, particularly, across hierarchy of 
authority, gender, position, nature and structure of the organization.

- Traits or characteristics of a typical bully/mob, otherwise known as perpetrator.

- $\quad$ Strategies/Tactics used by the perpetrator (bully/mob) to victimize and target individuals and/or group at workplace.

\section{The Terms Conflict}

The real conflict existed in the literature to express the concept of bullying at work. However, mobbing could not be separated to define workplace targeting by coworkers. Hence, with great difficulty the terms are accepted to mean the act of emotional abuse so prevalent in organizations (Zapf, 1999). Few of the researchers in the field of workplace conflict treat bullying and mobbing as synonyms, whereas others recognize that these two terms point to different kinds of aggression (Davenport et al., 1999).

Bullying and mobbing, both forms of aggression are worth studying, as both do serious harm to the victims, social relations and productivity at workplace. Furthermore, nowadays researchers do not distinguish between the two terms because the basic criteria characterizing situations of mobbing and bullying appeared to be the same (Einarsen, et al., 2003).

\subsection{Prevalence of Emotional Abuse: Bulling/Mobbing}

It is difficult to measure the extent of bullying/ mobbing in a workplace or organization because it depends to a fair extent on self-reporting, and the definitions or attributes of bullying/ mobbing used in employee surveys. Salin (2004) found that different perceptions of the levels of bullying depended on the criteria or definition applied by the researcher. Professional employees who were given a general definition of bullying and then asked if they had been bullied indicated much lower level of bullying (8.8 per cent) than those who were provided a list of pre-defined negative acts and then asked which they had experienced (24 per cent). Moreover, some researchers believe bullying/mobbing is greatly under-reported, perhaps for the reasons noted by Egan (2005) and others (Lipsett, 2005; Lutgen-Sandvik, 2003) that targets withdraw perceiving that they are at fault or that there is no possible redress (Wornham, 2003).

Moreover, if unrecognized, ignored or accepted bullying can become rooted in organization's culture as spiraling fear and copycat behaviors develop so that underreporting occurs simply because employees accept bullying as the norm (Shallcross, 2003; Lutgen-Sandvik, 2003). At one place in the literature it was read that the changing nature of work and increasing demands on organizations to meet relentless pressures for reduced costs, especially in the form of increased labor productivity, act to boost the likelihood and acceptance of bullying (Wornham, 2003).

\subsection{Traits of the Bully/Mob (Perpetrator)}

Bullies/Mobs are very good at convincing others, including coworkers and mangers, 
that the victim deserve the abuse that they are subjected to. As the attacks continue day in and day out the target begins to be worn down and eventually will make a mistake. Perhaps, they will have an emotional outburst and lash back at the bully/mob (Einarsen, 2000).

It is proven through various researches (Ashforth, 1995; Silver 1990; Rayner and Hoel, 1997) that a typical bully/ mob appears to lack insight into his or her behavior and seems to be unaware to the crudeness and incompatibility thereof. If the bullies/mobs know what they are doing, they are responsible for their behavior and thus liable for its consequences to other people. An effective bully must be a master of disguise and covert operations. There are certain characteristics common to a bully/mob that makes $\mathrm{him} / \mathrm{her}$ successful in bullying/mobbing at workplace. Following traits of a typical bully/mob is identified through intensive literature and resources: Charming in Public, RumorMonger in Private, Two-Faced; Distorts Truth and Reality; Hypocritical; Evasive; Pompous; Self-Righteous and Plays the Victim.

\subsection{Strategies of Bulling/Mobbing at Workplace}

Keashly and Jagatic (2003) analyzed surveys conducted by different researchers across various workplaces that categorized a wide range of aggressive workplace interactions. Although too extensive to list here, the examples of workplace abuse clearly conform to Zapf's (as cited in Einarsen et.al. 2003) five major categories that constitute workplace mobbing strategies as follows:

1. Changing work tasks in some negative way and/or making them difficult to perform;

2. Social isolation by not communicating or exclusion;

3. Personal attacks through ridicule or insulting remarks;

4. Verbal threats through criticism or humiliation in public; and

5. Spreading of rumors.

Individually, these categories may seem trivial within the holistic context of the workplace, however, it is the culmination of progressive loss of control over their work responsibilities and the persistent humiliation that eventually wears away the target's confidence and self-esteem. Ironically, empirical studies have demonstrated that targets of such abusive and humiliating behavior are those that are average to high achievers (Westhues, 2004), with personal characteristics of enthusiasm, integrity and commitment to their work (Davenport et.al. 2002:82; Shallcross 2005; 2006). Gellner and Hirsch, (2001) states, that targets exhibit specific personality traits that include a strong sense of right and wrong, ethical values, compassion, logic, imagination and lateral thinking problemsolving skills. Such attributes, which may be perceived as 'threatening' by co-workers and challenge the status quo, would not constitute grounds for dismissal. Instead, the target is subjected to bullying/ mobbing behaviour in the hope that the 'committed high achiever' will voluntarily leave (Zapf and Einarsen 2003). 


\subsection{Effects of Emotional abuse: Workplace Bulling/Mobbing}

As is authenticated by skimming through the literature that emotional abuse is not only under projected, reported and recognized, but its effects are also under scrutinized, weighted and minimized, despite being more devastating in long-term projections (Zapf and Einarsen 2003). Emotional abuse, if frequent enough, is usually internalized by the victim, and leaves them feeling fearful, insignificant, unworthy, untrusting, emotionally needy, undeserving and unlovable, and as if they were bad, deserving of punishment, and to blame (Gellner and Hirsch, 2001).

The cost of bullying/mobbing in the workplace is high; both in terms of psychological and physical consequences to the individual and in terms of financial and legal costs to the organization (Adams, 1992; Rayner et. al, 1999; Crawford, 1997). The impact and cost of bulling/ mobbing at work needs to be considered both at the individual and the workplace levels. Studies highlight that there are a number of individual and organizational consequences associated with bullying/mobbing.

Reading through the literature it was observed that survivors of emotional abuse often have a hard time understanding why they feel so bad (Felson and Tedeschi, 1993). A climate of disregard for a person's feelings, where one is subjected to constant or frequent criticisms, being yelled at, or being ignored, has a deep and profound effect, attacking the very self-image and confidence of a person.

Workplace bullying/mobbing covers a wide array of targeted, persistent and severely destructive behaviors, usually by managers towards their subordinates (McCarthy et al., 2003). Further elaborating on the cost areas, the organizations suffer from productivity loss, turnover, and increased legal and insurance costs. There are also considerable costs to individuals and the ethical capital of organizations, but this is more difficult to measure (Institute of Personnel and Development, 1996).

\section{Research Methodology}

\subsection{Sampling Frame}

Before putting in process the data collection procedures, the researcher would like to describe the sample design and sampling frame that has been used to collect the data. The sampling frame for the researcher was from the corporate, IT, medical and educational institution. A total of 235 sample size was made accessible from the defined sampling frame. The researcher, during the preliminary secondary research has identified five factors that can be used to analyze the existence of workplace emotional abuse in the form of bullying/mobbing. Also, to make the research more valid and reliable, the researcher interviewed 58 victims of emotional abuse (respondents).

\subsection{Data Collection}

Data collection methods are important after the sampling frame has been identified. 
The research adapted primarily Qualitative and Quantitative (only numeric form of data analysis with no statistical tool or methodology used for data interpretation) for research data analysis and interpretation. The main difference between qualitative and quantitative research is not quality but procedure. In qualitative research, findings are not arrived at by statistical methods or other procedures or quantification. The difference between quantitative and qualitative methods is not just a question of quantification but also a reflection of different perspectives on knowledge and research objectives. The research approach used to study the investigation into bullying/mobbing is exploratory in nature since the data collection for relied on international surveys, documentation, archival records, interviews, direct observations, participant-observation, and physical artifacts.

The demographic profiling of respondents is given below with a detailed analysis:

\section{Data Analysis}

\section{Respondents' Demographics \\ Figure 5-1 Respondents' Highest Qualification}

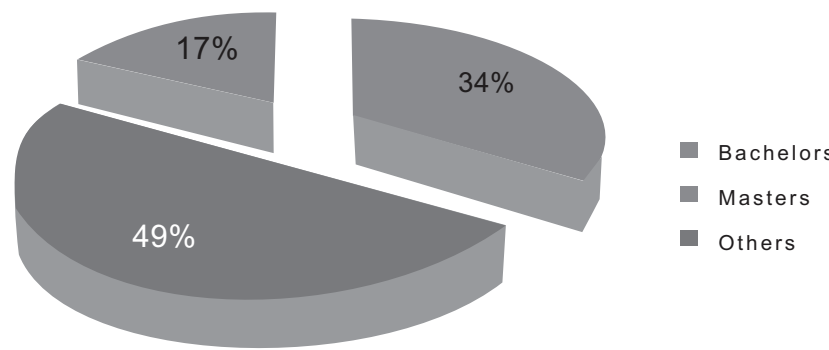

Figure 5-1 shows the highest qualification of total respondents of 235 working people, where $34 \%$ of the respondents had earned their Bachelors and $49 \%$ respondents being Masters in their respective field of interest and education. Whereas, $9 \%$ were considered the rest comprising of academic backgrounds from the field of medicine, accountancy, consultancy, M Phil, PhD, etc.

Figure 5-2 Respondents' Age Profile

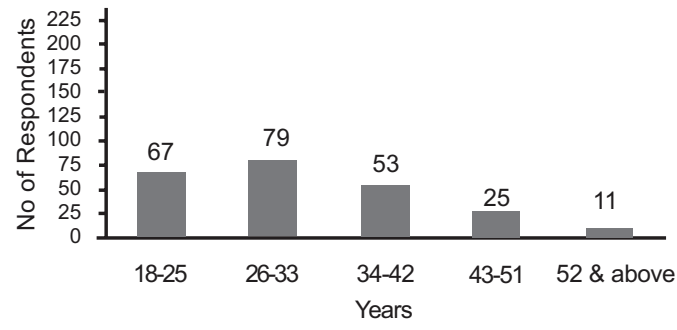

Figure 5-2 shows the age bracket of the respondent where the highest portion of response, $45 \%$ (146 respondents) was from the age bracket of 18 to 33 years followed by a $23 \%$ respondents from working people with the age bracket of 33 to 42 . $13 \%$ of 
the respondents were aged 43 to 51 years and only $5 \%$ respondents were 52 years and above.

Figure 5-3 Respondents' Gender

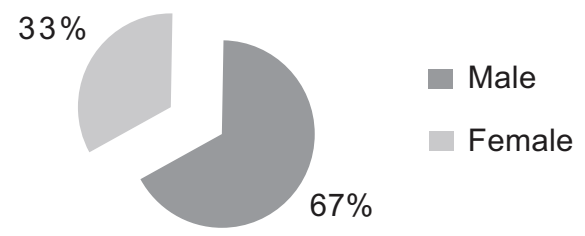

Figure 5-3 shows the respondent gender type where it is seen that out 235 total respondents, $67 \%$ (157 respondents) are male whereas, the rest of the $33 \%$ are female respondents.

Figure5-4 Respondents' Nature of Organization

Private Goverment $\quad$ Other

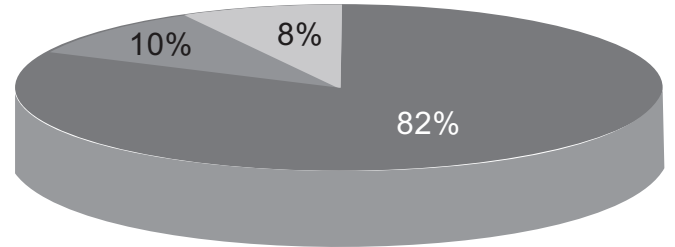

Figure 5-4 shows the nature of organization in which the respondents are currently working for. The results shows that $82 \%$ of the respondents are working in private sector and only $10 \%$ are working in government, whereas, only $8 \%$ of the respondents are working in semi-government organizations or as entrepreneurs or in some other professions.

Figure 5-5 Respondents' Industry of Employment

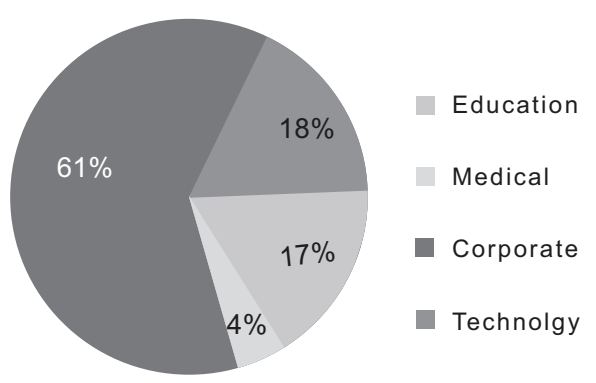


Figure 5-5 shows the respondents industry of employment by sector. The results shows that the majority $(61 \%)$ of the respondents are working in a corporate (banks, telecommunication, manufacturing, FMCGs, Pharmaceutical, etc.) whereas $18 \%$ of the respondents were from the IT or Technological sector. Other $17 \%$ working for the education sector including schools, colleges and universities and the rest (4\%) were working in the medical fields as consultants, doctors/nurses, associate professors and front desk help.

Figure 5-6 Respondents' Position in the Organization

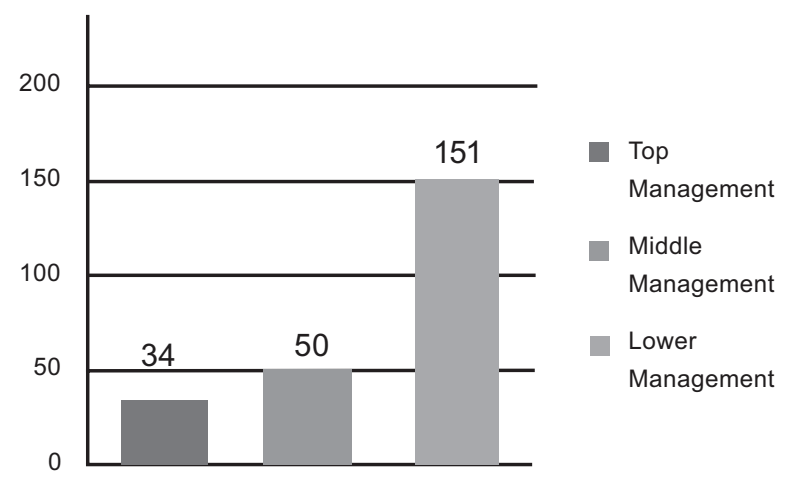

Figure 5-6 shows the respondents' position in the organization in which they are working. Majority of the respondents (64\%) are currently working in the lower level positions as junior executives, officers, trainees and assistant manager. This is also authenticated through their years of services, income and age bracket in the demographic profiling. $21 \%$ of the respondents were from the middle management representing managerial and senior management positions and the rest (14\%) were top management including CEOs, Directors, owners, etc.

\section{Terms Conflict}

Figure 5-7 Respondents' familiarity with the terms

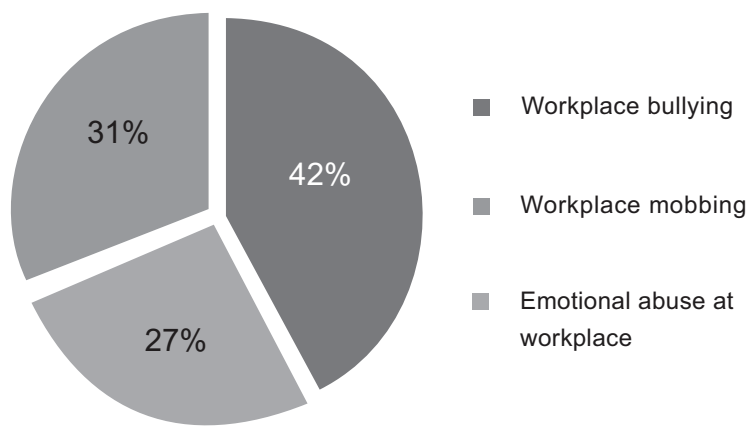


Figure 5-7 shows 3 terms that are used to describe workplace harassment: emotional abuse, mobbing and bullying. Respondents were asked about their understanding of these 3 terms and it was found that overall $42 \%$ of the respondents had come across the term 'bullying' and may have considered it anything ranging from leg pulling to bad mouthing the colleagues/subordinates. Another 31\% agreed to have heard about the term 'emotional abuse' and have considered as anything ranging from sexual abuse to abuse of authority. Only $27 \%$ respondents had any idea about the term 'mobbing' that was not clearly projected but most who agreed defined mobbing as accusing/ deceiving the employees/coworkers.

Prevalence of Bullying/Mobbing

Figure 5-8 Mistreatments at Workplace

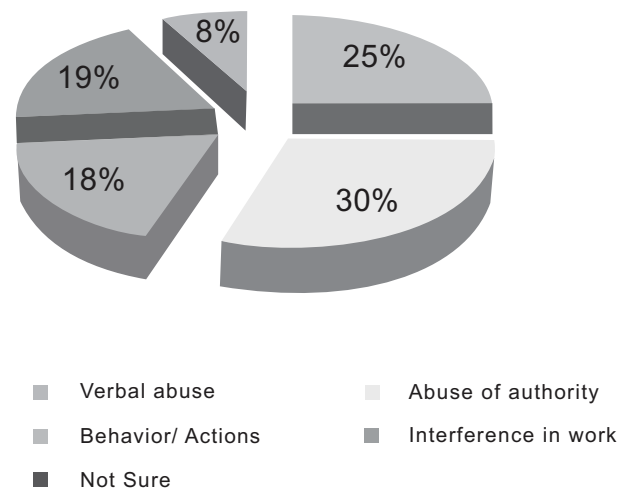

Figure 5-8 shows the types of mistreatments generally observed in workplaces where the respondents were asked to highlight the most prominent mistreatments that they have witnessed or experienced during their work period. It was found that the highest mistreatment was due to Abuse of Authority, which was $30 \%$ of the overall response. Whereas, Verbal Abuse was $25 \%$ of the overall response and the second most frequent. The Behavior/Action Abuse and Interference in work were both closely equally responded at $18 \%$ and $19 \%$. The rest of the $8 \%$ were not sure if they could identify the abuse.

Figure 5-9 Respondents' Experience/Witness of Bullying/Mobbing

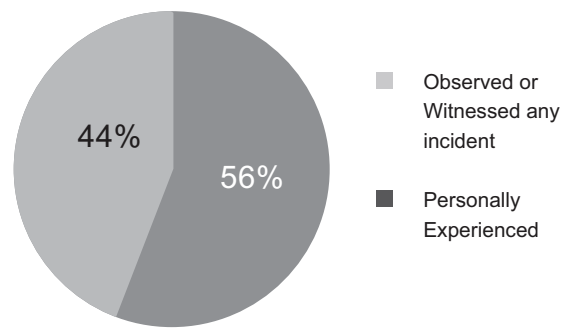


Figure 5-9, shows the prevalence of workplace bullying/mobbing and respondents' consent to its existence in their organization. Approximately, $56 \%$ of the respondents agreed to have witnessed bullying/mobbing in workplace (after being given a definition of workplace bullying/mobbing). Whereas, the remaining $44 \%$ respondents, agreed to have had experienced some kind of bullying/mobbing behavior, from within the organizational set-up.

Figure 5-10 Frequency of Bullying/Mobbing in Workplace

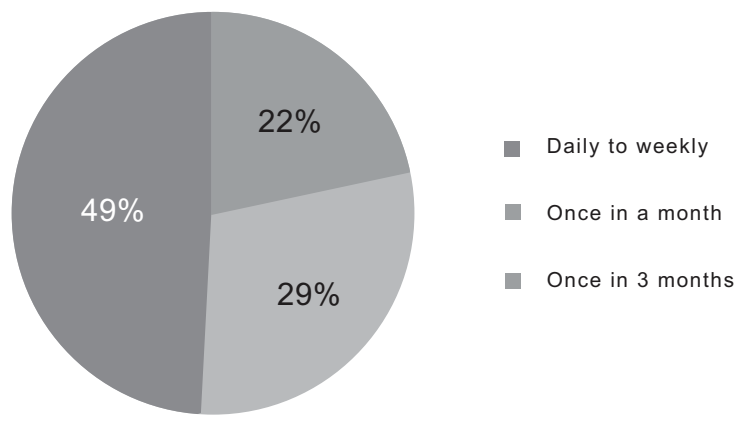

Figure 5-10 shows the frequency of bullying/mobbing taking place in the respective respondents' organizations. It was found that a majority (46\%) agreed that bullying/mobbing in their workplace was observed/ experienced at least once per month. Whereas, $32 \%$ agreed that bullying/mobbing in their workplace is a regular event of the day and occurs on routine basis or weekly. Only the rest of the $20 \%$ said that bullying/mobbing was not very frequent and would occur once or twice in a given quarter. The analysis reflects that people in the lower position and not having authority to make decisions were more frequent victims to bullying/mobbing occurring on routine or regular basis.

\section{Figure 5-11 Bullying/Mobbing Treatment}

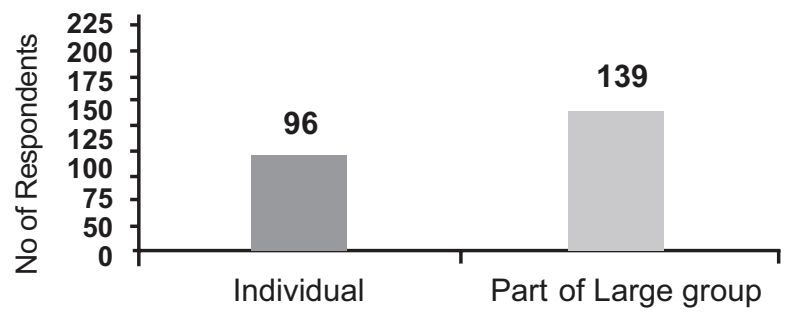

Figure 5-11 shows the bullying/mobbing treatment of the respondents/victims as a group or individually. It is clearly reflected that $59 \%$ of the respondents considered themselves being bullied/mobbed as a group and the rest (31\%) considered to have been targeted individually and attacked and humiliated at workplace. 
Figure 5-12 Position of the Bully/Mob (Perpetrator)

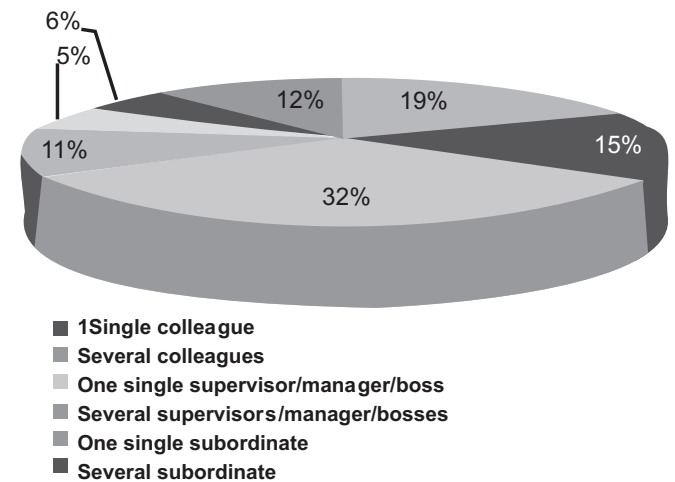

Figure 5-12 shows the position of the perpetrator and the respondents'/victims' reply on the statements. It was found through the overall analysis of data that $32 \%$ of the overall respondents agreed to have been bullied by one single boss/supervisor; followed by $19 \%$ of being victimized by one single colleague to a $15 \%$ response on being mobbed by several colleagues. $12 \%$ of the respondents from the corporate sector claimed to have been victimized by clients and customers and $11 \%$ agreed to have been bullied/mobbed by several bosses/supervisors. Moreover, only a negligible per cent of $11 \%$ agreed to have been targeted for bullying/mobbing by subordinate(s).

Figure 5-13 Gender of the Perpetrator

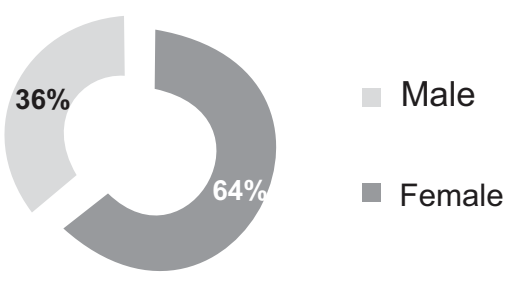

Figure 5-13 shows the gender of the perpetrator (bully/mob) victimizing the coworkers at the workplace. It was found that respondents agreed that $64 \%$ of the bully/mob were males and the rest $36 \%$ were female. Usually, female in higher positions mobbed other females in lower positions, and males in higher positions mobbed females in both higher and lower positions. 
Figure 5-14 Position and Gender of the Bully/Mob

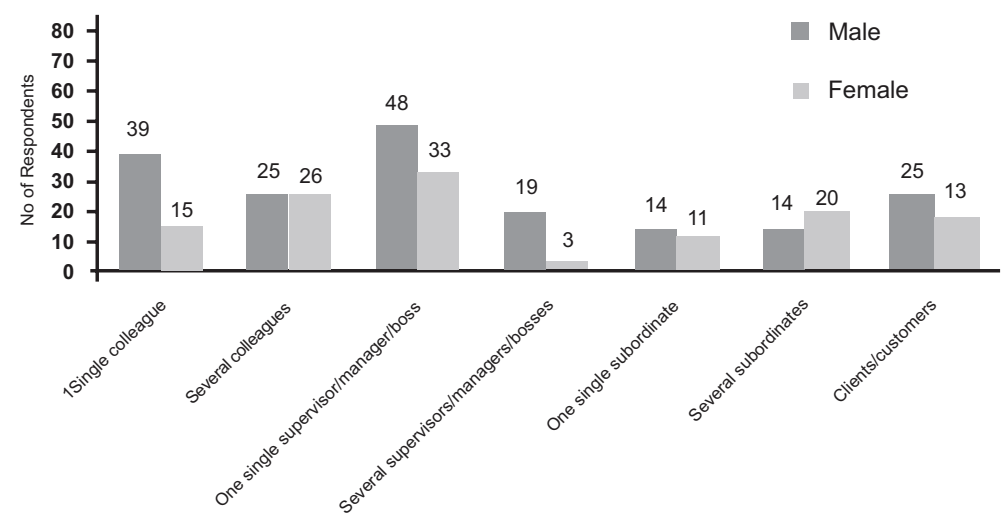

Figure 5-14 shows an aggregate analysis of figure 3-21 and 3-22 a, where each identified position is seen with a gender perspective. The data analysis shows that mostly males bullied/mobbed as single colleagues, single and several bosses as well as clients. On the contrary, females bullied as part of several colleagues, single bosses and several subordinates. This clearly shows that males bullied/mobbed more than females due to long-term perspective to working and growing within the organization and having good relationship across the organizational and diplomatic skills.

Figure 5-15 Significant Traits of the Bully/Mob
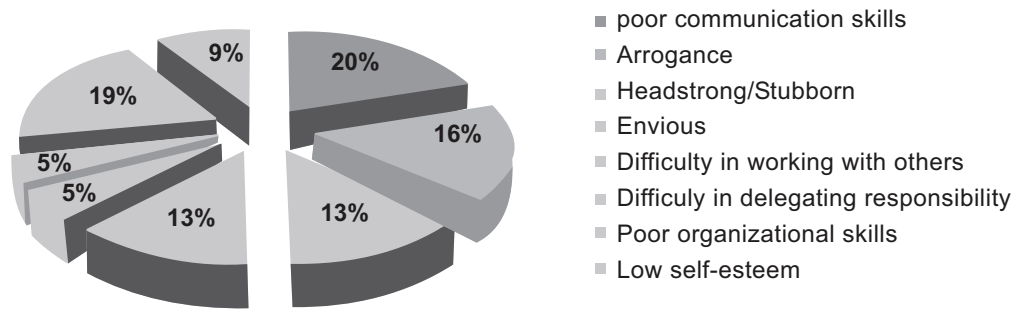

Figure 5-15, shows a trait of typical bully/mob has been enlisted to be agreed or disagreed with. Here the respondents were asked to identify the most significant characteristic of the bully/mob. It was found that mostly all the traits are significant to a typical bully but arrogance (16\%), poor organizational skills $(19 \%)$ and poor communication skills $(20 \%)$ were considered as the most common in a bully/mob. 
Figure 5-16 Ways to Tackle Bullying/Mobbing

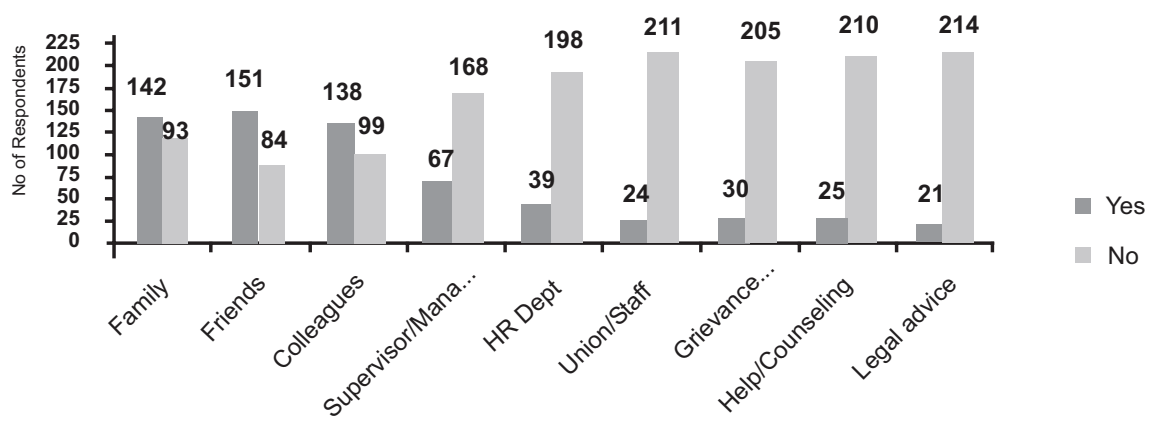

Figure 5-16 shows the ways the victims tackled being bullied/mobbed. People who voiced against being bullied could have done the following: talked to Family, Friends, trusted Colleagues, Supervisors, HR Department, Union, Grievance Procedure, Counseling, and Legal Advice. It was found that mostly victims discussed their case with trusted friends, usually family members and trusted colleagues to help them cope with the bullying behavior and conditions at workplace.

Figure 5-17 Company Policy on Workplace Bullying/Mobbing

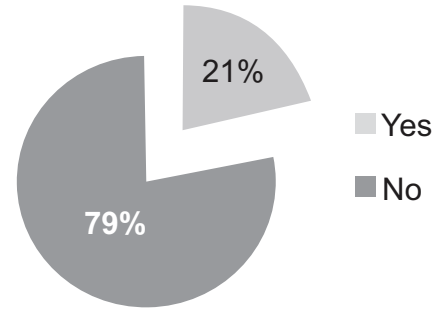

Figure 5-17 shows if company has any formal workplace bullying/mobbing policies in place. It was found that a majority $(79 \%)$ of the respondents agreed that their organizations did not had any formal policy to combat the bully or the bulling behavior. Whereas, the rest of the $21 \%$ agreed that their organizations have policies for workplace harassment and mistreatment, covering some aspects of bullying and mobbing.

Figure 5-18 Significant Self Conditions after being bullied/ mobbed

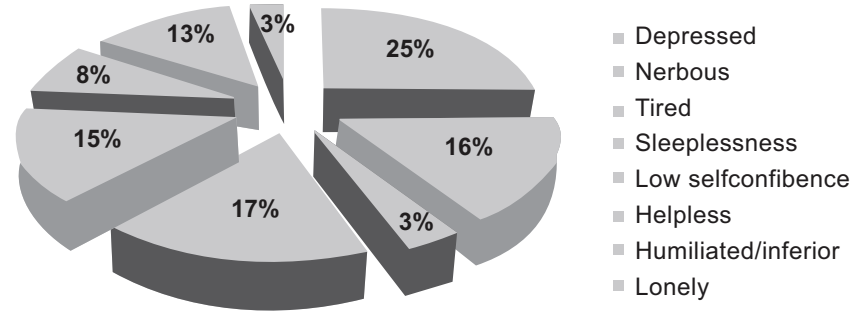


Figure 5-18, shows the significance of most prominent self conditions that were observed/experienced by the victims. The data analysis and dissection shows that the most significant self condition was depression, contributing to $25 \%$ of the overall responses followed by sleeplessness that was $17 \%$ responded leading to $16 \%$ responses on nervousness in doing work and $15 \%$ responses on affecting self confidence of the victims at the workplace.

Figure 5-19 Significance Aftermaths of Bullying/Mobbing
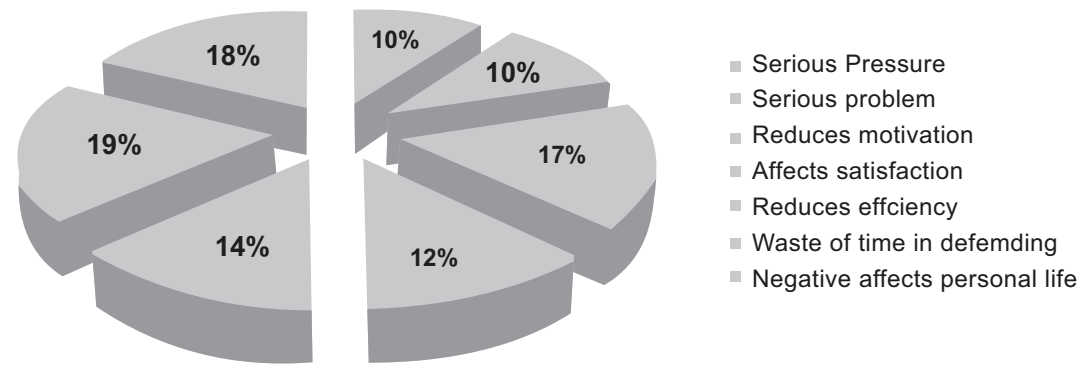

IFigure 5-19, shows the most commonly significant consequences of workplace bullying/mobbing. It was found after aggregate analysis that the top three effects of bullying to one's quality of life were, waste of time in defending oneself (19\% responses), followed by negative effects on personal life as well as health (18\% responses) and then the reduced motivation to work and contribute ( $17 \%$ responses).

Figure 5-20 Strategies for Bullying/Mobbing

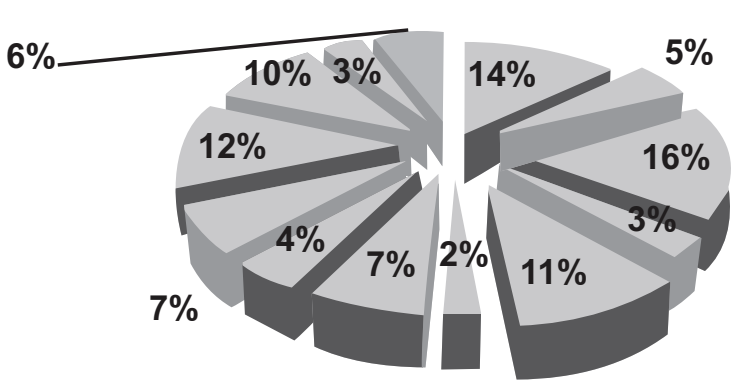

\footnotetext{
- Unfair Assessment

- Threats

verbalv Abuse

- Physical Abuse

- Biased Treatment

- Deception/Monitoring

- Unreasonable assignments

Silent treatment

Exclusion/insulting gestures

- Profane behaviors

Withering communication

- Personal attack

- Refusals to benefits/incentives
}

Figure 5-20 shows the responses of the participants on the various strategies used by the bully/mob to victimize the individual or group at workplace. After data analysis it was found out that six types of strategies took the lead when it comes to workplace bullying/ mobbing. Top of the strategies, Verbal Abuse (16\% respondents agreeing to it) as the most frequently used tactic by the bully/mob.) Unfair assessment of efforts 
(14\% respondents agreeing to it), especially from the supervisor or management and usually in the private sector, where career progress and development mainly depends on evaluations and appraisals. Profane behaviors including such as provocative jokes/notes, insulting remarks, were used with skill and diplomacy to humiliate and hence was ranked as the third most powerful tactic in bullying/mobbing the victims/targets. $11 \%$ of the respondents agreed that Biased Treatment (less favorable from coworkers) was considered as the third most frequently used tactic to undermine or degrade the victim in the course of bullying/mobbing. $10 \%$ of the respondents consented that cyber bullying through electronic mediums, like withering phone calls, emails, letters, faxes, etc. had been increasingly used as a medium for bullying/mobbing coworkers, especially from the formal line of commands, and across lateral levels.

\section{Conclusions}

It was analyzed that bullying/mobbing was initially used by Heinz Leymann to describe an experience he encountered while researching the social dynamics of the workplace. Apparently, it is always observed that bullies (perpetrator) are very good at convincing others, including colleagues and superiors, that the victim deserves the abuse that they are subjected to. As a result of this, the victim begins to feel depressed and exhausted, hence ineffective and inefficient at work. Workplace bullying is often passed off as 'tough management' a personality conflict or is seen as being brought on by the victimized employee. It is imperative to highlight that bullying/mobbing is different from other conflict situations in the workplace, which usually involve coworkers who disagree on certain topics, goals or desired directions. Stress caused by workplace abuse has a cumulative impact on a person's physical and emotional well-being because it is almost always ongoing and unrelenting. Decreased job performance, depression, feelings of helplessness, isolation, anxiety and fear are some of the emotional affects of workplace abuse.

\section{Recommendations}

- $\quad$ Establish a bullying/mobbing free culture.

- $\quad$ Seriousness of the management is required in addressing the issue of emotional abuse at workplace that shapes up into bullying/mobbing.

- $\quad$ Organizations need to introduce transparent and fair policies on bullying/mobbing.

- $\quad$ Organization, especially the HR function, should ensure a 'safe' reporting procedure for bullying/mobbing

- $\quad$ Alteration in the management styles are required, understanding the nature of the organization's existence.

- $\quad$ Organizations can offer stress management programs and skill development programs to the bully/mobs as well as the victims/targets

- $\quad$ Preventive work must involve organizational leadership (management and employees) working together to develop a shared vision 
- Develop an organizational culture that does not tolerate aggression and behaviorally supports employees in dealing with it.

- $\quad$ Provision of counseling and recovery time, as well as rehabilitation to dealing with emotional abuse should be provided to the victims/targets.

- Holistic approach embracing a culture of fair dealing in managing employment equity, diversity and employee recruitment, performance, development and promotion

- Bullying/Mobbing is a clear discrimination in the workplace that should be manifested in human resources management policies and practices.

- $\quad$ The toxic effects of bullying/mobbing, both upon the individual and its potential impact on the organization, should be openly communicated.

- Implement a 360o evaluation program that considers input from peers, subordinates as well as superiors.

\section{Areas of future Research}

The area of future research could be to find out subjectivity and objectivity of workplace emotional abuse and how bullying can retard the leadership process to mere victimization. By ignoring or overlooking this menacing practice, instead of creating leaders, the organizations are harnessing bullies to bring ultimate doom to the existence of workplace sanity. 


\section{References}

Adams A. (1992), Bullying at Work: How to Confront and Overcome It, London: Virago.

Ashforth, B. E., Humphrey, R. H. (1995), 'Emotion in the work place: a reappraisal', Human Relations, Vol. 48 pp.97-125.

Bjorkqvist, K., Osterman, K., \& Hjelt-Back, M. (1994). Aggression among university employees. Aggressive Behavior, 20, 173-184.

Crawford I. (1997), 'Bullying at work: a psychoanalytic perspective,' European Journal of Work and Organizational Psychology, Vol. 7, pp. 219-225.

Davenport N, Schwartz R. D, Elliot G. P. (2002), Mobbing: Emotional Abuse in the American Workplace. lowa: Civil Society Publishing.

Davenport N, Schwartz R. D. and Elliott G. P. (1999), Mobbing: Emotional Abuse in the American Workplace (Ames, IA: Civil Society Publishing).

Egan, K. (2005). 'Bullying: Know Thy Enemy', recorded address of presentation to Unions NSW Workshop, Handling Bullying Complaints the Easy Way, Sydney 18 March, Red Tape, 2005 April/May.

Einarsen S, Hoel, H, Zapf D, Cooper C. L. (eds.) (2003) Bullying and Emotional Abuse in the Workplace, London: Taylor and Francis.

Einarsen, S. (2000), 'Bullying and harassment at work: a review of the Scandinavian approach,' Aggression and Violent Behavior, Vol. 5, No. 4; pp. 379-401.

Einarsen, S., Raknes, B.I. (1997), "Harassment in the workplace and the victimization of men", Violence and Victims, Vol. 12 pp.247-63.

Felson, R. B., and Tedeschi, J. T. (1993), Aggression and Violence: Social interactionists' Perspectives, Washington, DC: American Psychological Association.

Gellner D, and Hirsch E. (2001), Inside Organisations: Anthropologists at work, Oxford: Berg.

Institute of Personnel and Development, (1996), News release, London: IPD House.

Keashly, L., \& Harvey, S. (2006). Workplace emotional abuse. In E. Kelloway, J. Barling \& J. Hurrell Jr. (Eds.), Handbook of workplace violence (pp. 95-I20). Thousand Oaks:SAGE Publications.

Leymann, H. (1990), Handbok for anvandning av LIPT-formularet for kartlagning av risker for psykiskt vald (Manual of the LIPT Questionnaire for Assessing the Risk of 
Psychological Violence at Work), Violen, Stockholm.

Lipsett, A. (2005), 'The university of hard knocks and heartache', THES, 16 September.

Lutgen-Sandvik, P. (2003), 'The communicative cycle of employee abuse: generation and regeneration of workplace mistreatment', Management Communication Quarterly, Vol.16, No. 4, pp.471-501.

McCarthy, P, Mayhew, C., Barker, M., and Sheehan, M. (2003), 'Bullying and occupational violence in tertiary education: risk factors, perpetrators and prevention, Journal of Occupational Health and Safety Australia and New Zealand, Vol.19, No. 4, pp.319-26.

Mikkelsen, E.G., Einarsen, S. (2001), "Bullying in Danish work-life: prevalence and health correlates", European Journal of Work and Organizational Psychology, Vol. 10 No.4, pp.393-413.

O'Moore, M., Seigne, E., McGuire, L., \& Smith, M. (1998). Victims of bullying at work in Ireland. The Journal of Occupational Health and Safety - Australia and New Zealand, $14,569-574$.

Rayner, C., Sheehan, M., and Barker, M. (1999), 'Theoretical approaches to the study of bullying at work,' International Journal of Manpower, Vol. 20, pp. 11-15.

Rayner C. and Hoel H. (1997), 'A summary review of literature relating to workplace bullying,' Journal of Community and Applied Social Psychology, Vol. 7, pp. 181-191.

Salin, D. (2004), 'Bullying and organizational politics in competitive and rapidly changing work environments,' International Journal of Management and Decision-Making, Vol. 4, No. 1, pp. 35-46.

Schat, A.C.H., Kelloway, E.K. (2003), "Reducing the adverse consequences of workplace aggression and violence: the buffering effects of organizations", Journal of Occupational Health Psychology, Vol. 8 No.5, pp.110-22.

Shallcross, L. (2003), 'The workplace mobbing syndrome: response and prevention in the public sector, Paper presented to Workplace Bullying: A Community Response Conference, Brisbane, pp. 16-17.

Shallcross L. (2005), 'Workplace mobbing: social exclusion, women and work,' Unpublished paper presented at The 4th International Interdisciplinary Conference the Gender, Work and Organization, Keele University, UK.

Shallcross L. (2006), The workplace mobbing syndrome: response and prevention in the public sector,' International Journal of Organizational Behaviour.

Silver, H. K., and Glicken, A. D. (1990), 'Medical student abuse: Incidence, severity, 
and significance,' Journal of the American Medical Association, pp. 263, 527-532.

Vartia, M. 1996. "The Sources of Bullying: Psychological Work Environment and Organisational Climate." European Journal of Work and Organizational Psychology, 5 (2), 203-214

Westhues K, (ed.) (2004) Workplace Mobbing in Academe: Reports from Twenty Universities, New York: Edwin Mellen Press.

Wornham, D. A. (2003), 'A Descriptive investigation of morality and victimisation at work', Journal of Business Ethics, June, Vol. 45, No. 1, pp.29-40.

Zapf, D., Einarsen, S., Hoel, H. and Vartia, M. (2003), 'Emprical findings on bullying in the workplace', in S. Einarsen, H. Hoel, D. Zapf and C.L. Cooper (Eds.) Bullying and Emotional Abuse at Work: International Perspectives in Research and Practice, London: Taylor and Francis.

Zapf, D. (1999), "Organizational Work group related and personal causes of mobbing/bullying at work", International Journal of Manpower, Vol. 20 No.2, pp.70-85.

Zapf, D., Knorz, C., Kulla, M. (1996), "On the relationship between mobbing factors, and job content, social work and health outcomes", The European Work and Organizational psychologist, Vol. 5 No.2, pp. 215-37. 